\title{
Pedagogia dos multiletramentos na educação integral
}

\author{
Pedagogía de los multiletramientos en la educación integral \\ Pedagogy of multiliteracies in integral education
}

\author{
Lic. Aline Moura Domingues Marsico ${ }^{1}$ \\ Dr. Mauricio Aires Vieira ${ }^{2}$
}

\begin{abstract}
Resumo
O presente estudo originou-se a partir do Programa de Educação Tutorial (PET)- Pedagogia e está vinculado à Universidade Federal do Pampa, Câmpus Jaguarão/RS. A pesquisa central do PET é o fracasso/sucesso escolar na Educação Básica, das escolas públicas de Jaguarão/RS, tomando por base os dados de avaliação de desempenho escolar divulgados pelo IDEB. Para pesquisar o porquê desse fracasso e do sucesso escolar desse município, iniciaram-se observações nas escolas. Simultaneamente, quando se iniciou as observações, estava em andamento um programa na escola, conhecido como Programa Mais Educação (PME), que foi e está sendo implantado com o intuito de iniciar uma política rumo à Educação Integral. Esta pesquisa ficará restrita ao macrocampo Acompanhamento Pedagógico, em Letramento/Alfabetização. Para contribuir com a escola e o programa, utilizou-se de pesquisa bibliográfica, de natureza qualitativa, em que aplicou-se um questionário com 08 (oito) sujeitos envolvidos, para investigar se conheciam o PME. Após esse diagnóstico, surgiu o interesse em pesquisar o letramento, mais especificamente, o multiletramento, com o intuito de verificar se há atividades específicas para trabalhar o multiletramento no $6^{\circ}$ ao $9^{\circ}$ ano, na perspectiva da Educação Integral, nas escolas públicas de Jaguarão/RS. Caso não as encontrasse, seria proposta uma atividade para ser trabalhada com o multiletramento no PME. Os resultados do questionário apontaram que a maioria dos sujeitos desconhecia o PME. Com relação a atividades sobre multiletramento, estas estão circulando, por exemplo, em Rojo e Moura (2012), mas não encontrou-se direcionadas para o PME. Diante disso, propôs-se o protótipo: gênero biografia/facebook.
\end{abstract}

Palavras-chave: Programa Mais Educação. Multiletramento. Protótipos.

\section{Resumen}

El presente estudio origina-se a partir del Programa de Educação Tutorial (PET) Pedagogía y está vinculado a la Universidade Federal do Pampa, Ciudad Jaguarão/RS. La pesquisa central es el fracaso/suceso escolar em La Educación Básica das escuelas públicas de Jaguarão/RS,, tornando por base los dados de evaluación de lo desempeño escolar divulgados pelo IDEB. Para pesquisar el porqué de ese fracaso y del suceso escolar de eso município iniciarán-se observaciones en las escuelas. Simultáneamente, cuando se inició lãs observaciones, estaba em andamiento un programa en la escuela, conocido como el Programa Mais Educação (PME), que fue y está siendo implantado con el intuito de iniciar una política rumo a la Educación Integral. Esta pesquisa se quedará restricta al macrocampo acompañamiento pedagógico, en Letramientó/Alfabetización. Para contribuir con la escuela y el programa, utilizó se dé pesquisa bibliográfica, de naturaleza cualitativa, en que se aplicó um cuestionario con 08 (ocho) sujetos envueltos, para investigar se conocían el PME. A pues ese diagnóstico surge com el interesse en pesquisar el letramientó, más específicamente el multiletramento, con el intuito de ser verificar se hay actividades específicas para trabajar o multiletramento no $6^{\circ}$ al $9^{\circ}$ año, en la perspectiva de la Educación Integral, en las escuelas públicas de Jaguarão/RS. Caso no fue posible, será propuesta una actividad para ser trabajada con el multiletramento no PME. Los resultados del cuestionario apuntaran que la mayoría delos sujetos desconocía el PME. Conrelación no hayactividades sobre elmultiletramento, estas están circulando,

\footnotetext{
${ }^{1}$ Licenciada em Letras Português/Espanhol e suas respectivas literaturas, Universidade Federal do Pampa Brasil, alinemouradomingues@gmail.com.
}

${ }^{2}$ Doutor em Educação, Universidade Federal do Pampa - Brasil, mau.vieira@gmail.com. 
por ejemplo, en Rojo y Moura (2012), mas no encuéntrese direccionadas para el PME. Luego, propuse el prototipo: género biografía/facebook.

Palabras-clave: Multiletramento. Programa Mais Educação. Prototipos.

\begin{abstract}
This presente article originated by the Programa de Educação Tutorial (PET) - Pedagogia and is link by the Universidade Federal do Pampa - Campus Jaguarão/RS. The principal research of the PET is the educational failure/success on the basic school, on the publics schools from Jaguarão/RS, taking by base the avaliation dates from the scholar performance released by the IDEB. To research the cause off this failure and this success on this city, has started the observation on thas schools. Simultaneously, when started the observation, whas happening in the school one program know how Programa Mais Educação (PME), who was implanted whith the objective to start a politic by integral education. This research will be limited by the macrocamp pedagogical monitoring, in literacy. To contribute with the school and the program, was used from bibliografic research, from qualitative nature, who has applied one quis whis 08 (eight) involved subjects, to investigate if they know the PME. After this diagnostics, born the interest in research the literacy, more specifically the multiliteracy, whit the objective to verify if have specific activities to work the multiliteracy on the $6^{\circ}$ and $9^{\circ}$ year, on the perspectiv of the Integral Education, on the public schools of Jaguarao/RS. If whe don't find the activities, will be propose one to be worked with the multiliteracy on the PME. The results of the quiz pointed by the mosto $\mathrm{f}$ the sujects unknow the PME. With relation on the multiliteracy activities, this was circulating, like in Rojo and Moura (2012), but we don't find activities directed by the PME $>$ By this, was proposed the prototype genre biografy/facebook.
\end{abstract}

KeyWords: Programa Mais Educação, multiliteracy, prototype

\title{
INTRODUÇÃO
}

O presente estudo originou-se a partir do Programa de Educação Tutorial (PET), o qual foi difundido no Brasil, ainda, na ditadura militar, em 1979. O PET tem como objetivo principal incentivar e promover a formação de profissionais com excelência acadêmica. Além disso, busca interagir com a comunidade através de atividades por meio do ensino, pesquisa e extensão nas múltiplas facetas de que o conhecimento da universidade se apresenta.

Há vários grupos PET formados e que estão em plena atividade no Brasil. Um deles é o PET-Pedagogia, o qual participo, e que está vinculado à Universidade Federal do Pampa, Câmpus Jaguarão/RS. O grupo começou em dezembro/2009 e a pesquisa central é o fracasso/sucesso escolar na Educação Básica, de Jaguarão/RS, tornando por base os dados de avaliação de desempenho escolar divulgados pelo $\mathrm{IDEB}^{3}$. Os últimos dados analisados pelo Grupo PET, através do IDEB foram no ano de 2013, e Jaguarão/RS ficou entre os mais baixos percentuais do estado do Rio Grande do Sul, computando $2,3^{4}$.

Para pesquisar o porquê desse fracasso e do sucesso escolar desse município, o grupo juntamente com o Tutor Maurício Aires Vieira iniciaram observações nas escolas.

\footnotetext{
3“O Índice de Desenvolvimento da Educação Básica (IDEB) foi criado pelo INEP em 2007 e representa a iniciativa pioneira de reunir em um só indicador dois conceitos igualmente importantes para a qualidade da educação: fluxo escolar e médias de desempenho nas avaliações." (IDEB, 2014). Para maiores informações, o site do IDEB é: http://portal.inep.gov.br/web/portal-ideb/portal-ideb. Para verificar os resultados, pode-se encontrá-los no site: http://ideb.inep.gov.br/resultado/resultado/resultado.seam?cid=2666477.

${ }^{4}$ Este resultado refere-se aos anos finais do ensino fundamental do município de Jaguarão/RS.
} 
Simultaneamente, quando se iniciou as observações, estava em andamento um programa na escola, conhecido como Programa Mais Educação (PME), que foi e está sendo implantado com o intuito de iniciar uma política rumo à educação integral. $O$ seu surgimento primeiramente se deu somente em escolas com menores IDEBs. Hoje, quase todas as escolas estaduais e municipais de Jaguarão/RS já aderiram ao programa.

Como o município de Jaguarão/RS apresenta um baixo número no IDEB, o PME almeja melhorar no sentido de contribuir para a diminuição das desigualdades educacionais e sociais. Dessa forma, possibilitará aos educandos das unidades escolares das redes pública o acesso a um ensino de qualidade, acrescentando ao currículo escolar tradicional conhecimentos teóricos e práticos que devem ser desenvolvidos por meio de atividades complementares.

A portaria interministerial $\mathrm{n}^{\mathbf{0}} 17$, de 24 de abril de 2007, apresentam algumas finalidades do PME, que são:

[...] ampliação do tempo e do espaço educativo e a extensão do ambiente escolar nas redes públicas de educação básica de Estados, Distrito Federal e municípios, mediante a realização de atividades no contraturno escolar, articulando ações desenvolvidas pelos Ministérios integrantes do Programa; II - contribuir para a redução da evasão, da reprovação, da distorção idade/série, mediante a implementação deações pedagógicas para melhoria de condições para o rendimento e o aproveitamento escolar [...]. (BRASIL, lei no 17, de 24 de abril de 2007, p. 2-3).

Foram apresentadas algumas intenções do PME presentes na portaria. Pode-se verificar alguns princípios da educação integral na esfera do PME presentes no decreto no 7.083, de 27 de janeiro de 2010:

[...] oferecer atendimento educacional especializado às crianças, adolescentes e jovens com necessidades educacionais especiais, integrado à proposta curricular das escolas de ensino regular o convívio com adiversidade de expressões e linguagens corporais, inclusive mediante ações de acessibilidade voltadas àqueles com deficiência ou com mobilidade reduzida; V - promover a formação da sensibilidade, da percepção e da expressão de crianças, adolescentes e jovens nas linguagens artísticas, literárias e estéticas, aproximando o ambiente educacional da diversidade cultural brasileira, estimulando a sensorialidade, a leitura e a criatividade em torno das atividades escolares; [...]. (BRASIL, lei nº 7.083, de 27 de janeiro de 2010, p. 1).

A partir do momento em que se conhece o que é, qual a intencionalidade e a finalidade do programa, parte-se para os macrocampos. De acordo como Caderno Passo a Passo (s.d), o PME é composto por 10 macrocampos, que são: acompanhamento pedagógico, educação ambiental, esporte e lazer, direitos humanos em educação, cultura e artes, inclusão digital, 
promoção da saúde, educomunicação, investigação no campo das ciências da natureza e educação econômica e cidadania. Cada macrocampo organizado por diferentes atividades.

O macrocampo Acompanhamento Pedagógico é obrigatório. Este deve englobar pelo menos um desses temas: ciências, história e geografia, letramento/alfabetização, língua estrangeira, matemática, tecnologias de apoio à alfabetização (CADERNO PASSO A PASSO, s.d.).

Dentre esses macrocampos, a presente pesquisa ficará restrita ao do Acompanhamento Pedagógico, em Letramento/Alfabetização. E qual o conceito de letramento? Este é por profissionais de áreas diversas. Na área da educação, por exemplo, destaca-se Soares (2003, p. 18), que o define como:

[...] é palavra e conceito recentes, introduzidos na linguagem da educação e das ciências lingüísticas (sic) há pouco mais de duas décadas; seu surgimento pode ser interpretado como decorrência da necessidade de configurar e nomear comportamentos e práticas sociais na área da leitura e da escrita que ultrapassem o domínio do sistema alfabético e ortográfico, nível de aprendizagem da língua escrita perseguido, tradicionalmente, pelo processo de alfabetização. (SOARES, 2004, p.18).

Na área da Linguística, Kleiman (2008, p. 18) aponta que letramento pode ser definido “[...] como um conjunto de práticas sociais que usam a escrita, como sistema simbólico e como tecnologia, em contextos específicos, para objetivos específicos". Percebe-se, assim, que apesar de o termo letramento ser usado em áreas distintas, este tem como foco central a leitura e a escrita como prática social.

No Manual do PME (2013, p.11), a oficina de letramento/alfabetização também tem por objetivo desenvolver a "[...] função social como meio da inserção do estudante, sujeito de direito. [Além disso, é direcionada para a] Compreensão e produção de textos de diferentes gêneros em situações comunicativas, tanto na modalidade escrita quanto na modalidade oral."

\section{Problematização e justificativa}

O interesse em Letramento/Alfabetização adveio de uma série de dificuldades observadas na execução de oficinas ministradas por três colaboradores, em uma escola municipal de Jaguarão/RS. Entre essas dificuldades, pode-se citar alunos com faixas etárias e anos/séries $\left(1^{\circ}, 6^{\circ}, 7^{\circ}\right.$ e $8^{\circ}$ anos/séries) diversos, os colaboradores não apresentavam um planejamento prévio, alguns colaboradores desistiam de ministrar as atividades, não havia espaço físico adequado, entre outros. 
Para contribuir com a escola e o programa, apliquei um questionário com 10 (oito) sujeitos envolvidos 05 (cinco) alunos, 02 (dois) monitores, 1 (um) professor comunitário, 01 (uma) supervisora, 01 (um) funcionário), para investigar se sabiam a respeito do PME. No primeiro momento, o instrumento serviu para investigar as possibilidades na contribuição da amenização ou minimização das dificuldades.

No segundo momento, após a identificação, o grupo juntamente com o tutor, criaram um grupo de estudos denominado Grupo de Estudos da Educação Integral de Fronteira (GEEIF) $^{5}$ que, no ano de 2013, não obteve muito sucesso. A procura pelo grupo foi baixa e em situações flutuantes (um pequeno grupo diferente se reunia a cada semana no desenvolvimento do Grupo de Estudos). Por esse motivo, surgiu uma nova proposta: o I Seminário Internacional da Educação Integral de Fronteira (SIEIF), oportunidade esta em que diversas escolas mostraram suas experiências e conseguiram debater com profissionais de distintos lugares a questão da educação integral, do Programa Mais Educação, dos macrocampos e também das questões ligadas ao letramento.

O problema trazido nesta pesquisa é: como trabalhar o multiletramento do $6^{\circ}$ ao $9^{\circ}$ ano na perspectiva da Educação Integral, nas escolas públicas de Jaguarão/RS?, para auxiliar a amenizar o baixo índice do IDEB. Conforme Kleiman (2005, p.16), ““[...] ensinar o letramento' é uma expressão no mínimo estranha, pois implica uma ação que ninguém, nem mesmo um especialista, poderia fazer". Especialmente, porque "o letramento é complexo, envolvendo muito mais do que uma habilidade (ou conjunto de habilidades) ou uma competência do sujeito que lê. Envolve múltiplas capacidades e conhecimentos para mobilizar essas capacidades.” (KLEIMAN, 2005, p.18).

Já se sabe que o letramento é uma prática difícil de ser atingida. E o multiletramento, por contemplar a multiculturalidade e a multimodalidade, influenciadas pela globalização, é outro desafio muito maior. Segundo Rojo e Moura (2012), trabalhar com multiletramento:

[...] pode ou não envolver (normalmente envolverá) o uso das novas tecnologias de comunicação e de informação ("novos letramentos"), mas caracteriza-se como um trabalho que parte das culturas de referências do alunado (popular, local ou de massa) e de gêneros, mídias e linguagens por eles conhecidos, para buscar um enfoque crítico, pluralista, ético e democrático - que envolva agência - de textos/discursivos que ampliem o repertório cultural, na direção de outros

\footnotetext{
${ }^{5}$ GEEIF (Grupo de Estudos da Educação Integral na Fronteira), grupo criado pelo PET para realizar discussões e palestras sobre o tema Educação Integral e o programa Mais Educação, destinado a acadêmicos, oficineiros, professores e demais interessados na temática. O GEEIF teve início no mês de junho de 2013 e encerrou no mês de dezembro de 2013. O encontro acontecia todas as segundas-feiras, das $18 \mathrm{~h} 30 \mathrm{~min}$ às $21 \mathrm{~h}$, na Universidade Federal do Pampa.
} 
letramentos, valorizados (como é o caso dos trabalhos com hiper e manocontos ${ }^{6}$ ou desvalorizados (como é o caso do trabalho com picho ${ }^{7}$ ). (ROJO, MOURA, 2012, p. 8).

Acredita-se, pelo motivo de normalmente envolver as tecnologias, a dificuldade, por parte do professor, de proporcionar atividades que parta do conhecimento de mundo do aluno, transformando, assim, essas linguagens com o enfoque crítico. Espera-se que este tema seja relevante tanto no âmbito acadêmico quanto para os profissionais atuantes e envolvidos no PME apresentando alguns exemplos de atividade a serem trabalhadas com o multiletramento em sala de aula.

Sabendo que o município de Jaguarão/RS apresenta um IDEB baixo, no ensino fundamental, verifica-se a necessidade da presente pesquisa para contribuir na melhora desse índice. E, consequentemente, na melhoria do ensino e aprendizagem dos jovens e crianças jaguarenses, com o multiletramento.

\section{Objetivos}

O objetivo principal deste trabalho é pesquisar e analisar acervos bibliográficos que abordem a temática do multiletramento. Além disso, busca verificar se há atividades específicas para trabalhar o multiletramento no PME. Considerando os conceitos da palavra letramento/multiletramento, pretende-se refletir sobre as atividades encontradas sobre o tema, para o PME. Caso não for possível, será proposta uma atividade para ser trabalhada com o multiletramento no PME.

\section{Metodologia}

A pesquisa apresentada trata de estudo acerca do conceito de Multiletramento e como este está sendo apresentado por Rojo e Moura (2012). Para fazer a pesquisa do multiletramento, pretende-se analisar livros, teses, artigos científicos, entre outros. Já para o PME e Educação Integral, além dos materiais bibliográficos já citados, terão decretos, portarias interministeriais, manuais e entre outros.

As atividades serão identificadas se estão adequadas para o Multiletramento. Após será verificado se as mesmas podem ser trabalhadas no PME entre os anos do $6^{\circ}$ ao $9^{\circ}$ ano do

\footnotetext{
6 "miniconto, microconto ou manoconto é uma espécie de conto muito pequeno, com algumas características bem específicas” Portal do Professor, 2014. Disponível em:

<http://portaldoprofessor.mec.gov.br/fichaTecnicaAula.html?aula=9804>. Acesso em: 12 dez. 2014.

7 "Significado de picho: 1. Pichel; 2. Pequeno pote de barro; 3. Carrapicho de cabelo no alto da cabeça; 4. Chocolateira.". Dicionário do Aurélio, 2014. Disponível em: http://www.dicionariodoaurelio.com/picho. Acesso em: 12 dez. 2015.
} 
PME/Educação Integral. Os critérios a serem adotados consistem em verificar se as atividades abordam a multiculturalidade e a multimodalidade, além de ser interativa. Os critérios para o PME versam no sentido se as atividades servem para turmas heterogêneas.

O presente estudo tem caráter qualitativo, no sentido de exemplificar como essas atividades são abordadas nesses anos da escola. Além disso, é pesquisa do tipo bibliográfica que, conforme aponta Silva e Grigolo (2002, p. 33), consiste na procura de referências teóricas publicadas em livros, artigos, periódicos, documentos, legislações, sites institucionais, etc., para que o pesquisador "[...] tome conhecimento e analise as contribuições científicas aos assuntos em questão.”

\section{Roteiro}

O presente trabalho está dividido em quatro partes. Na primeira parte, serão descritos os conceitos de Programa de Educação Tutorial e Educação Integral. Na segunda parte, serão abordadas as definições de Letramento, novos conceitos de letramento e multiletramento. $\mathrm{Na}$ terceira parte, será exposta a teoria do gênero discursivo. Na quarta parte, serão apresentados e discutidos os dados da pesquisa. E, finalmente, serão expostas algumas considerações finais e/ou recomendações à luz do multiletramento e educação integral.

\section{PROGRAMA DE EDUCAÇÃO TUTORIAL}

O Programa de Educação Tutorial (PET) foi constituído na ditadura militar no ano de 1979 pela CAPES, na época, denominado como Programa Especial de Treinamento. Após sua implementação, o programa atravessou por períodos complexos, inclusive, foi ameaçado de extinção. De acordo com Castro ${ }^{8}, 2002$ (apud MÜLLER, 2003, p. 107) houve dois motivos fundamentais para essa ameaça:

[...] houve dois motivos: um pessoal e outro político. Como sabemos, as pessoas que estavam na CAPES não achavam que o PET pudesse melhorar a graduação. Quanto à política, não havia uma tendência a se substituir o livro e o homem pela máquina. Acho que a vontade de acabar com o PET pode ser fruto dessa maneira de se qualificar o ensino por meio de máquinas e não de pessoas [...]. (CASTRO, 2002 apud MÜLLER, 2003, p. 107).

Para que de fato não ocorresse a extinção do programa, todos os envolvidos, como tutores e petianos, mobilizaram-se para defendê-lo, visto que esse grupo possibilita ampliar o conhecimento através da relação existente entre os componentes do PET. Após esse confronto com políticos, o programa passou a ser gerenciado pela SESu/MEC pelo motivo que:

${ }^{8}$ CASTRO, Gabriel Perfeito. Uma vontade latente. Brasília, 25 de mar. 2002. 
[...] a CAPES acreditava que o programa fugia à sua seara, pois o PET é voltado para a graduação e a CAPES se destina a atender o ensino pós-graduado. Essa questão foi solucionada com a transferência do programa para a SESu. Houve crescente falta de apoio, desprestígio do PET como um todo, pela nova administração da CAPES. A título de saber exatamente quais eram os resultados que o PET vinha produzindo, essa administração resolveu, o que foi de uma boa iniciativa, fazer uma avaliação dos resultados globais do programa. (PIMENTA ${ }^{9}$, 2002, apud MÜLLER, 2003, p. 129).

A partir desse momento, ficou acordado de que quem realizasse os processos seletivos para o ingresso de bolsistas no grupo, fosse de cada instituição. Além disso, de que era necessário entregar um relatório anual sobre as atividades desenvolvidas pelo grupo. Para compor o PET, são selecionados em média 12 (doze) bolsistas remunerados, podendo ter até 6 (seis) bolsistas voluntários cadastrados. Todos devem ter as melhores notas e possuírem/trabalharem na esteira da excelência em ensino, pesquisa e extensão, além de outras atividades que fortaleçam o espírito de grupo, equipe, liderança e apoio nas mais diversas áreas da graduação.

Pimenta (2002) comenta com relação ao objetivo do PET:

[...] o grande objetivo do PET era premiar o talento, fornecendo-lhe condições para desabrochar. Por isso, não havia como o programa ser aberto a todos, nem se expandir infinitamente. A massificação contradiz um dos pressupostos do programa, que é a formação com qualidade. Portanto, por que não se falar de uma elite? Bolsistas como os do PET fazem parte de uma elite intelectual que discute questões sociais, inclusive. E isso, além de importante para formar lideranças comprometidas com a comunidade, é muito raro. Ademais, o tom pejorativo com que alguns se referem ao elitismo do PET não condiz com a realidade, na medida em que não só os bolsistas tinham acesso ao programa. (PIMENTA, 2002, apud MÜLLER, 2003, p. 131).

Todos os grupos passam por avaliações, desde o planejamento que deve ser encaminhado até o relatório final das atividades realizadas. $O$ grupo PET é remodelado/readequado se algum bolsista integrante for reprovado em dois ou mais componentes curriculares ou se não desempenhar adequadamente todas as atividades propostas, sob as orientações do tutor.

O programa possibilita transformar o educando, pois permite que o bolsista cumpra suas atividades como pesquisador com segurança, com atividades de extensão em contato com a comunidade. Além disso, habita o petiano a defender suas opiniões além de se colocarse criticamente dentro da universidade e do mundo. Eu, como petiana, nada notei de fato

\footnotetext{
${ }^{9}$ PIMENTA, Antônio Newton da Rocha. Sem argumentos. Brasília, 28 de mar. 2002.
} 
negativo para participar do grupo, pois o programa autoriza a organização de eventos, minicursos, palestras entre outras atividades que auxiliam na formação do acadêmico.

O grupo PET-Pedagogia da Universidade Federal do Pampa/Campus Jaguarão é tutoreado por Maurício Aires Vieira e atualmente, 2014, o grupo está formado por 10 (dez) bolsistas, em fase de ingresso de dois bolsistas e não conta, no momento, com voluntários. $\mathrm{O}$ foco de pesquisa é "O sucesso/fracasso escolar dos aprendentes e ensinantes, contribuindo para a minimização/redução da evasão/retenção escolar. Atualmente aprofunda estudos na temática do Programa Mais Educação e Educação Integral em regiões de fronteira." (BLOG PET PEDAGOGIA, 2014).

As atividades que o grupo realiza são:

[...] apresentação de trabalhos acadêmicos/científicos em eventos nacionais/internacionais; participação, promoção e organização de eventos acadêmicos, minicursos, palestras e oficinas; leitura e discussão de obras científicas, com o intuito de auxiliar na pesquisa tema do grupo; desenvolvimento de projetos de extensão junto à comunidade externa. (BLOG PET PEDAGOGIA, 2014).

O PET permite a convivência com tutores e bolsistas inclusive de outras regiões brasileiras. Possibilita uma troca de culturas, uma interculturalidade, que ajuda na formação acadêmica. Os grupos petianos em geral promovem não apenas a formação acadêmica, mas também a pessoal.

Nas próximas seções, será exposta por diferentes autores como Moll (2009), Teixeira (1962), Arroyo (2013) e entre outros as visões em relação ao programa mais educação. Conforme as metas propostas no PNE (2014), a meta 6, é “Oferecer Educação em tempo integral em, no mínimo, 50\% das escolas públicas, de forma a atender, pelo menos, 25\% dos(as) alunos(as) da Educação Básica.” (BRASIL, 20014, p. 10). Nesse sentido, pode-se afirmar que o PME serviu como uma política que induziu a Educação Integral. O grupo está aprofundando seus estudos acerca dessa temática.

\section{CONHECENDO O PROGRAMA MAIS EDUCAÇÃO}

O PME foi criado em 2007, a partir da Portaria Normativa Interministerial $\mathrm{n}^{\circ} .17$, de 24 de abril de 2007 (BRASIL, 2007), e aprovado pelo presidente Luís Inácio Lula da Silva, tendo como objetivo resolver os problemas que assolam absolutamente a Educação Brasileira.

Com a criação dessa portaria, o Governo Federal pôde: 
[...] instituir o Programa Mais Educação, com o objetivo de contribuir para a formação integral de crianças,adolescentes e jovens, por meio da articulação de ações, de projetos e de programas do Governo Federal esuas contribuições às propostas, visões e práticas curriculares das redes públicas de ensino e das escolas,alterando o ambiente escolar e ampliando a oferta de saberes, métodos, processos e conteúdos educativos [...] (BRASIL, 2007, p. 2).

Como se percebe, o PME é uma estratégia de implantação e implementação da Educação Integral no Brasil. Além do objetivo supracitado, o PME visa a um ensino interdisciplinar, que seja realizado em distintos ambientes e com o uso de diferentes metodologias. Esse programa não foi pensado de imediato. Surgiu desde os Centros Integrados de Educação Pública (CIEPs) com as escolas de tempo integral. Na década de 80, quem tinha o direito à uma escola em tempo integral, era a classe alta, pois tinha condições de manter os filhos em escolas privadas. Atualmente, esse programa vai além e até o encerramento da lei vigente do Plano Nacional da Educação (PNE), todas as escolas deverão estar oferecendo educação integral.

Na perspectiva de Moll (2009, p. 12):

O que se caracteriza como uma educação integral, mediante o legado desses pensadores e as mudanças dos contextos históricos, é o reconhecimento da necessidade de ampliar e qualificar o tempo escolar, superando o caráter parcial e limitado que as poucas horas diárias proporcionam, em estreita associação com o reconhecimento das múltiplas dimensões que caracterizam os seres humanos. (MOLL, 2009, p. 12).

Quando a autora aborda em ampliar a jornada escolar, significa que o tempo que será destinado a mais, deve ser exposto atividades que acrescente conhecimento ao aluno. Não significa "mais do mesmo" e sim oficinas que possibilitem um arranjo maior. Como pode-se analisar no PNE (2014), além das metas que incluem a Educação Integral como algumas das prioridades, é legado que:

[...] educação integral requer mais que simplesmente a ampliação da jornada escolar diária, exigindo dos sistemas de ensino e seus profissionais, da sociedade em geral e dasdiferentes esferas de governo não só o compromisso para que a educação seja de tempo integral,mas também um projeto pedagógico diferenciado, a formação de seus agentes, a infraestrutura eos meios para sua implantação. (BRASIL, 2014, p. 28).

Precisa-se compreender os termos: escola de tempo integral e escola integral, que em sua nomenclatura se aproximam, porém seu sentido não é o mesmo. A escola de tempo integral necessariamente carece de um tempo a mais que se refere às escolas em geral. Já a escola integral, não é necessário deixar o aluno mais tempo na escola. Percebe-se que as 
atividades propostas conforme apresenta a lei tem que haver articulação das disciplinas que, no horário regular e no contraturno, haja um diálogo. Além disso, que utilize outros espaços (igreja, restaurante, hotel, teatro, entre outros), além da escola para que os alunos observem que lá fora existem outros conhecimentos, havendo assim uma integração entre os alunos e comunidade.

Segundo Teixeira (1962), na concepção de escola, essa deve ser voltada para a formação integral da criança:

A escola já não poderia ser a escola parcial de simples instrução dos filhos das famílias de classe média que ali iriam buscar a complementação daeducação recebida em casa, em estreita afinidade com o programa escolar, nas instituições destinadas a educar, no sentido mais lato da palavra... já não poderia ser a escola dominantemente de instrução de antigamente, mas fazer às vezes da casa, da família, da classe social e por fim da escola propriamente dita. (TEIXEIRA, 1962, p. 24).

Entendendo o que é educação integral, escola e formação do alunado, pode-se partir para os 10 (dez) macrocampos do PME. Cada um é composto por diferentes atividades. A escola que adere ao programa necessita escolher de 5 (cinco) a 6 (seis) atividades entre os 10 (dez) ou no mínimo 4 (quatro) macrocampos.

No entanto, o macrocampo acompanhamento pedagógico é obrigatório e deve englobar pelo menos um desses temas: ciências, história e geografia, letramento/alfabetização, língua estrangeira, matemática, tecnologias de apoio à alfabetização. Após a escola fazer a escolha dos macrocampos, o FNDE repassa o material e recursos financeiros necessários para a efetivação da oficina.

O PME tem como estratégia principal “[...] implementação de educação integral a partir da reunião dos projetos sociais desenvolvidos pelos ministérios envolvidos inicialmente para estudantes do ensino fundamental nas escolas de baixo IDEB." (BRASIL, 2009, p. 3). O PME aponta a promoção da educação integral à ampliação da jornada escolar de, no mínimo, sete horas diárias, com um novo desenho curricular e estrutural da escola, em todos os seus aspectos.

Dos macrocampos mencionados, esta pesquisa ficará restrita ao macrocampo acompanhamento pedagógico, especificamente, a oficina de letramento/alfabetização. Sendo assim, para desenvolver essa oficina, o ministério disponibiliza de kit (Figura 1) para a efetivação das oficinas. Estão inclusos nos kits da oficina de letramento/alfabetização, conforme apresentado no Manual Operacional do PME (2013): Alfabeto móvel em madeira 
ou plástico; Baralho de letras e palavras; Bingo de letras; Cartas para ditado; Dominó de leitura e escrita; Jogo cruza letras; Jogo da memória de sílabas; e Jogo primeiras palavras.

Figura 1 - Kit letramento

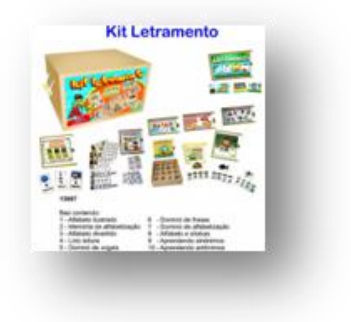

Fonte: MEC, 2014

O material, apresentado na figura 1, é o kit letramento, composto por diversos jogos didáticos. Na 3 seção a seguir, será exposto o conceito de letramento defendido por Soares (2006) e Kleiman (2008), após, será apresentado alguns "tipos" de letramentos, além das pedagogias dos multiletramentos.

\section{LETRAMENTO}

O termo letramento é muito recente. Ainda não se encontra uma definição nos dicionários, porém diferentes autores abordam sobre o assunto e/ou temática, como Soares (2006), da área da educação, e Kleiman (2008), da área da linguística.

Para Soares (2006), definir letramento é:

[...] uma tarefa altamente controversa; a formulação de uma definição que possa ser aceita sem restrições parece impossível. [...] Uma definição geral e amplamente aceita é necessária, especialmente quando se pretende avaliar e medir níveis de letramento: sem ela, como determinar critérios que estabeleçam a diferença entre letrado e iletrado, entre diferentes níveis de letramento?[...]. (SOARES, 2006, p. 86).

Como se pode perceber, não há uma definição concreta e aceita por todos. Porém, Soares $(2006$, p. 47) define que letramento seja “[...] o estado ou condição de quem não apenas sabe ler e escrever, mas cultiva as práticas sociais que usam a escrita." Nesse sentido, pode-se associar que letramento não seja somente o ato de ler e escrever, mas saber quando e como utilizá-lo.

Kleiman (2008, p. 20) explica que o “[...] fenômeno do letramento, então, extrapola o mundo da escrita tal qual ele é concebido pelas instituições que se encarregam de introduzirformalmente os sujeitos no mundo da escrita". Nesse contexto, pode-se fazer referência ao letramento e à escola, sendo que o letramento é um exercício com fins 
determinados e em situações específicas que abarcam a escrita, e a escola é um lugar que desempenha algumas práticas de letramento.

Soares (2006) e Kleiman (2008) abordam, em seus estudos, que nem todo o indivíduo alfabetizado pode ser considerado letrado. Mas, para analisar esses estudos, é necessário conhecer o que é alfabetização. Soares (2006) define que alfabetização é “[...] a ação de ensinar/aprender a ler e a escrever”. A partir dos conceitos apresentados de alfabetização e letramento, pode-se comparar o seguinte: alfabetização é ato de ler e escrever; já o letramento, é saber ler e escrever, tendo que decodificá-lo. Sendo que este pode variar "[...] conforme o contexto cultural e social, os interesses pessoais e as experiências de vida dos sujeitos envolvidos no processo de ensino e aprendizagem.” (PRIETO, 2013, p. 39).

A partir desses estudos sobre letramento e alfabetização, considera-se no presente trabalho que os dois conceitos apresentados, são relativamente distintos. Porém, há estudos mais avançados sobre letramento, os quais serão expostos nas subseções 3.1 e 3.2.

\subsection{Novos conceitos de letramento}

Os autores que abordam sobre o tema letramento, diferenciam-no em três tipos: letramento, letramentos múltiplos e multiletramento. O significado de letramento pode ser, como menciona Rojo (2009):

O 'significado do letramento' varia através dos tempos e das culturas e dentro de uma mesma cultura. Por isso, práticas tão diferentes, em contextos tão diferenciados, são vistas como letramento, embora diferentemente valorizadas e designando a seus participantes poderes também diversos (ROJO, 2009, p. 99).

Como já foi mencionado, alfabetização e letramento não são processos de seguimento, quer dizer, o letramento não é seguimento de alfabetização, nem vice-versa. Conforme Rojo (2009, p.98), “[...] é possível ser não escolarizado e analfabeto, mas participar, sobretudo nas grandes cidades, de práticas de letramento, sendo, assim, letrado de uma certa maneira". É necessário caracterizar como dois processos, “[...] pois uma pessoa pode ser alfabetizada e não ser letrada, assim como ser letrada e não ser alfabetizada.” (LEITE; BOTELHO, 2011, p. 10). A partir de então, letramento é uma prática social de leitura e escrita.

Os letramentos múltiplos, conforme Rojo e Moura (2012, p. 13), apontam para a “[...] multiplicidade e variedade de práticas letradas $[. .]$.$” . E o multiletramento é definido como:$ "[...] a multiplicidade cultural das populações e a multiplicidade semiótica de constituição dos textos por meio das quais ela se informa e se comunica." 
Sendo que esta pesquisa se aprofundará no termo multiletramento, será visto, na subseção 3.2, o surgimento do termo, quem o fundou e como ocorreu, o conceito, como funciona, como ocorre e os modos de comunicação, estes que ajudam na compreensão do termo multiletramento.

\subsection{Pedagogia dos Multiletramentos}

Rojo e Moura (2012, p.11) comenta que o termo Pedagogia dos Multiletramentos surgiu com o Grupo Nova Londres (GNL), em 1996. Este, conhecido como o grupo de pesquisadores de letramento de Londres. Após uma semana de discussão, foi publicado um manifesto intitulado Uma Pedagogia dos multiletramentos - desenhando futuros sociais. Esse manifesto serviu para “[...] afirmar a necessidade de a escola tornar a seu cargo os novos letramentos emergentes na sociedade contemporânea, em grande parte - mas não somente devido às novas Tecnologias da Informação e da Comunicação (TICS) [...]” (ROJO; MOURA 2012, p. 12).

Os estudos sobre o multiletramento teve início em 1996, pois já se pensava na “'[...] grande variedade de cultura já presentes na sala de aula de um mundo globalizado [...].” (ROJO; MOURA 2012, p. 12). Essas culturas e essa diversidade de práticas letradas proporcionaram o surgimento do termo multiletramento.

O grupo GNL apontava que era de importância trabalhar em sala de aula sobre os conflitos culturais. Alguns acreditavam que isso não era o ideal, pois, ao invés de apresentar, estaria incentivando os alunos a praticarem mais os conflitos. A partir de então, o GNL comentava que os alunos estavam tendo acesso:

[...] às novas ferramentas de acesso à comunicação e a informação e de agência social, que acarretavam novos letramentos, de caráter multimodal ou multissemiótico. Para abranger esses dois "multi" - a multiculturalidade características das sociedades globalizadas e a multimodalidade dos textos por meio dos quais a multiculturalidade se comunica e informa, o grupo cunhou o termo ou conceito novo: multiletramento. (ROJO; MOURA, 2012, p. 13).

Para entender o conceito do multiletramento, precisa-se reconhecer o termo multiculturalidade, que é caracterizado por envolver diferentes culturas em ambientes específicos. Assim a multimodalidade é qualificado por diferentes gêneros (foto, vídeos, gráficos entre outros). Existem alguns modos de comunicação que podem estar presentes tanto na multiculturalidade como na multimodalidade, como em qualquer outra comunicação, que pode-se verificar no Quadro 1: 
Quadro 1 - Modos de comunicação - multiletramento

\begin{tabular}{|l|l|}
\hline Escrita & Escrita e leitura - escrita à mão, página impressa, tela. \\
\hline Oral & Discurso ao vivo ou gravado. \\
\hline Visual & Imagem capturada ou em movimento, cena. \\
\hline Auditiva & Música, sons ambiente, barulhos. \\
\hline Tátil & $\begin{array}{l}\text { Toque, cheiro e gosto. } \\
\text { Gestual }\end{array}$ \\
Movimentos das mãos e dos braços, expressões do rosto, movimentos dos olhos, vestimenta, \\
\hline Espacial & $\begin{array}{l}\text { Proximidade, espaço, distância interpessoal, arquitetura, paisagem. } \\
\end{array}$ \\
\hline
\end{tabular}

Fonte: Rojo e Moura, 2012 (Adaptado de Cope e Kalantzis (2009, p. 178-179))

Além de se verificar os modos de comunicação existentes, estes são necessários para o entendimento de como ocorrem os multiletramentos, como é apresentado no Quadro 2:

Quadro 2 - Como ocorrem os multiletramentos

\begin{tabular}{|l|l|}
\hline Prática situada & $\begin{array}{l}\text { Imersão na experiência e utilização de discursos disponíveis, incluindo aqueles das } \\
\text { experiências de vida dos alunos, (experiência). }\end{array}$ \\
\hline Instrução explícita & $\begin{array}{l}\text { Compreensão consciente, analítica e sistemática. A utilização de uma linguagem } \\
\text { explícita para a construção do significado, (conceitualizar). }\end{array}$ \\
\hline $\begin{array}{l}\text { Enquadramento } \\
\text { crítico }\end{array}$ & $\begin{array}{l}\text { Interpretação do contexto cultural e social no qual o significado é construído (analisar). } \\
\text { Prática } \\
\text { transformada }\end{array}$ \\
$\begin{array}{l}\text { Transferência da prática da produção de significado para o trabalho em outros contextos } \\
\text { e locais culturais (aplicar). }\end{array}$ \\
\hline
\end{tabular}

Fonte: Rojo e Moura, 2012 (Adaptado de Cope e Kalantzis (2009, p. 184).

Para o leitor, é necessário o conhecimento dos modos de comunicação e como ocorre o multiletramento para análise dos protótipos. Chama-se protótipos as "[...] estruturas vazadas que permitem modificações por parte daqueles que queiram utilizá-la em outros contextos que não o da proposta inicial [...]” (ROJO; MOURA, 2012, p. 8). Além disso, esse conhecimento auxilia na compreensão dos “[...] textos compostos de muitas linguagens (ou 
modos, ou semiose) e que exigem capacidade e práticas de compreensão e produção de cada uma delas (multiletramentos) para fazer significar.” (ROJO; MOURA, 2012, p. 19).

Para o entendimento dos protótipos, é necessária a noção sobre gêneros discursivos (BAKHTIN, 2003). Esta é a discussão da seção 4.

\section{GÊERROS DISCURSIVOS}

De acordo com Bakhtin (2003, p. 279), “os gêneros são tipos relativamente estáveis de enunciados". Ou seja, em um discurso sempre haverá mudança, pois o tempo não será o mesmo, a entonação mudará, pode haver uma repetição ou uma retomada do discurso, mas este nunca será o mesmo. Por esse motivo, torna-se único e estável.

Conforme Bakhtin, os gêneros se dividem em primários e secundários. Os primários são os simples e os secundários são considerados os complexos. Os secundários fazem parte da comunicação científica, por exemplo, o romance, o teatro, entre outros. Os primários fazem parte do cotidiano, por exemplo, lista telefônica, a conversa entre amigos, dentre outros. Fazem parte do conteúdo do enunciado: conteúdo temático, estilo e construção composicional.

Para trabalhar com o gênero discursivo deve-se verificar o tema, forma composicional e o estilo, além do lugar ou esfera de circulação, o tempo e lugar histórico, os participantes envolvidos, o conteúdo e seu valor na sociedade.

Conforme Rojo e Moura(2012) em seu livro Multiletramentos na escola são expostos alguns protótipos desenvolvidos por seus alunos. Entre eles estão: Blog nos anos iniciais do fundamental I: a reconstrução de sentido de um clássico infantil; Chapeuzinho Vermelho na cibercultura: por uma educação linguística com multiletramentos; Minicontos multimodais: reescrevendo imagens cotidianas; Hipercontos multissemiótico: para a promoção dos multiletramentos; Projet(o) arte: uma proposta didática; Gêneros poéticos e interlace com gêneros multimodais;

Também apresenta no livro: $\mathrm{O}$ manguebeat nas aulas de português: videoclipe e movimento cultural em rede; a canção roda-viva: da leitura as leituras Documentário e pichação: a escrita na rua como produção multissemiótico; As múltiplas faces do Brasil em curta metragem: a construção do protagonismo juvenil e Radioblog: vozes e espaços de atuação cultural. Escolheu-se o protótipo radioblog, por ser uma das atividades desconhecidas para a pesquisadora. Esse protótipo foi desenvolvido como uma proposta para ser trabalhado no ensino fundamental ou ensino médio. 
As atividades ocorrem em forma de sequência didática da atividade 01 a 10 . O interessante dessas atividades é que primeiro analisa-se o conhecimento prévio dos alunos sobre o protótipo radioblog, após, apresentam-se alguns exemplos de rádio para que os alunos possam identificar qual poderia ajudar ou auxiliar na sua produção futura. Os temas podem ser escolhidos até mesmo a partir das redes sociais.

Esse protótipo apresenta a multiculturalidade, pois percebe-se quando mostra exemplos de rádios, (radialistas não se repete, como o lugar, o tempo, além de mostrar outras experiências, outras vivências. A atividade ajuda os alunos também no sentido da multimodalidade, pois são apresentados diversos recursos para a compreensão e, assim, auxiliar na escolha de seu tema. Na próxima seção, há apresentação de uma proposta de protótipo para ser aplicado no Programa Mais Educação.

\section{ANALISE E DISCUSÃO DOS DADOS}

Para a efetivação da pesquisa, em 2013, observei, durante nove meses (72h), uma vez por semana, as seguintes oficinas escolhidas pela escola: letramento/alfabetização, dança, futsal e banda.

Para contribuir com a escola e o programa, apliquei um questionário com 10 (oito) sujeitos envolvidos 05 (cinco) alunos, 02 (dois) monitores, 1 (um) professor comunitário) para investigar se conheciam o PME. No primeiro momento, o instrumento serviu para investigar as possibilidades na contribuição da amenização ou minimização das dificuldades.

A partir das respostas dos questionários, observou-se e constatou-se que existem algumas falhas/fragilidades e desafios/problemas a serem resolvidos. Alguns deles observados foram: que o entendimento das ações do programa era precário, não havia planejamento das atividades, não havia entendimento sobre escola integral e escola de tempo integral, além de haver muita troca de colaboradores/oficineiros, entre outros.

Após esse diagnóstico, verificou-se a necessidade de modelos de atividades para o programa, tendo como foco o multiletramento do $6^{\circ}$ ao $9^{\circ}$ ano da Educação Integral. Como até o momento, 2014, não existe um "manual" de protótipos possíveis para serem trabalhados o multiletramento/letramento na educação integral, busco, no presente trabalho, propor uma atividade para um futuro manual. O embasamento será nas atividades de Rojo e Moura (2012) do multiletramento na escola.

A atividade busca resgatar a biografia canônica e o facebook. Conforme Bakhtin "[...] moldamos o nosso discurso por determinadas formas de gênero, às vezes padronizadas e estereotipadas, às vezes mais flexíveis, plásticas e criativas" (BAKHTIN, 2003, p.282). Na 
atividade proposta vai se observar que o gênero biografia pode ser apresentado de duas maneiras com o suporte facebook.

A proposta terá 8(oito) passos, que serão os seguintes:

“Gênero biografia e facebook" - $1^{\circ}$ passo: Criação da conta ou atualização dos dados; $2^{\circ}$ passo: Apresentação do gênero biografia com alguns modelos; $3^{\circ}$ passo: é lançado o desafio, todos em sua linha do tempo (Facebook) deve: adicionar fotos, músicas ou vídeo, durante o período da atividade que será de uma semana; $4^{\circ}$ passo: Os alunos juntamente com a professora terão que criar uma biografia; após, esse modelo realizado em aula, a professora terá um grupo da disciplina que os alunos deverão através das publicações realizadas no facebook, criarem uma biografia do colega; $5^{\circ}$ passo: Após, cada um fará sua biografia e publicará no grupo; $6^{\circ}$ passo: Logo será realizado análise para verificar se os dois métodos realizados obtêm proximidades da questão da flexibilidade do gênero. Essa análise será realizada por outro colega; $7^{\circ}$ passo: A versão final da biografia será produzido por um aluno com as características do gênero e após será publicado e apresentado oralmente. $8^{\circ}$ passo: Apresentação oral entre os alunos.

Esse protótipo, conforme o multiletramento, visa “[...] educar os alunos para a capacidade e sensibilidade de lidar com a multiplicidade e complexidade do mundo, pois a diversidade linguística, semiótica e cultural se manifesta na escola, assim como fora dela. [...]" (ROJO E MOURA, 2012, p. 53). A proposta apresenta a multiculturalidade no sentido de apresentar diversas culturas, diversas identidades e para identificar essas culturas são mencionados e utilizados alguns recursos multimodais como vídeo, foto, o gênero biografia, entre outros, pois um complementa o outro.

Além disso, com esse protótipo, partiu-se do conhecimento do aluno, este, que é “[...] sujeito do seu próprio dizer/fazer, protagonista de seu percurso de aprendizagem [...]"(ROJO e MOURA, 2012, p. 92), que também utiliza essa ferramenta facebook até mesmo em sala de aula. Com o multiletramento, parte-se ou inicia-se do conhecimento prévio, conforme Rojo e Moura (2012, p. 53) comenta que:

[...] a pedagogia que leva em conta os multiletramentos incorpora a prática situada e embasada na experiência da criança, aberta a conceituação, que propõe o dialogismo e a análise crítica, transformando as práticas de leitura e escrita em práticas sociais que levem a construção e uso dos conhecimentos adquiridos. (ROJO E MOURA, 2012, p. 53).

O trabalho realizado com as ferramentas digitais são importantes de serem utilizadas na sala de aula, não como um instrumento qualquer, mas como forma de um objeto de ensino. 
Rojo e Moura (2012, p. 53) explicam que: existe uma necessidade de abusar das ferramentas digitais "[...] como um instrumento envolvidos nas práticas de letramento contemporâneo. Nesse, são apoio ao ensino, mas principalmente, são objetos de ensino”.

Além disso, esse protótipo auxilia no planejamento de novas práticas letradas, além de troca de experiências entre educandos e educadores. Com essa ferramenta e outras que podem ser utilizadas, é de suma importância que o educador obtenha conhecimento nas novas práticas de letramento.

\section{CONSIDERAÇÕES FINAIS}

Conforme o objetivo apresentado no início do trabalho, na procura de protótipos de multiletramento do $6^{\circ}$ ao $9^{\circ}$ ano para a Educação Integral, não se obteve êxito, pois de todos os materiais pesquisados e analisados, como em tese, artigos científicos, livros, entre outros, não se encontrou protótipos específicos do multiletramento para Educação Integral.

As atividades ou protótipos encontrados eram para o ensino fundamental e ensino médio, portanto, não foi analisado para ser trabalhado na Educação Integral. Por esse motivo, criou-se um protótipo nomeado "Gênero biografia e o facebook" destinado a alunos do $6^{\circ}$ ao $9^{\circ}$ ano para a Educação Integral. Como o nome é um protótipo, este pode ser utilizado com outro fim.

Esta pesquisa é importante, pois foram consultados diversos materiais que auxiliaram no entendimento, dentre eles, do PET, Programa Mais Educação, Multiletramento e escola. Assim pode contribuir na formação docente e continuada de profissionais de Letras, Pedagogia e outras áreas afins que atuam ou possam vir atuar nesse programa, o PME.

Acredito que o professor, independente da área, precisa estar satisfeito em sua profissão, dedicar-se sempre quando realizar as atividades, não ter medo se vai dar certo ou não e ter muita criatividade, para que o aluno sinta confiança e tenha vontade em participar das atividades ou protótipos propostos.

\section{REFERENCIAS}

BAKHTIN, Mikhail. Os gêneros do discurso. In:_. Estética da criação verbal. São Paulo: Martins Fontes, 2000, p. 279-287.

BLOG PET PEDAGOGIA, objetivos do grupo. Jaguarão, Agosto 2011. Disponível em: http://petunipampa-pedagogia.blogspot.com.br/p/objetivo-do-grupo.html. Acesso em: 12 nov. 2014. 
BRASIL, Decreto No 7.082, DE 27 DE JANEIRO DE 2010. Disponível em: http://www.planalto.gov.br/ccivil_03/_Ato2007-2010/2010/Decreto/D7082.htm Acesso em: 20 nov. 2014.

BRASIL. Plano Nacional da Educação 2014. Disponível em:

http://pne.mec.gov.br/images/pdf/pne_conhecendo_20_metas.pdf Acesso: 20 nov. 2014.

BRASIL. Portaria Normativa Interministerial $\mathbf{n}^{\mathbf{0}}$ 17, de 24 de abril de 2007. Disponível em: http://portal.mec.gov.br/arquivos/pdf/mais_educacao.pdf Acesso em: 20 nov. 2014. CADERNO PASSO A PASSO. Programa Mais Educação. s/d. Disponível em: https://www.google.com.br/portal.mec.gov.br\%2Findex.php\%3Foption\%3Dcom_docman\%2 6task\%3Ddoc_download. Acesso em: 1 nov. 2014.

CENTRO DE REFÊRENCIA EM EDUCAÇÃO INTEGRAL, Educação de tempo integral. Publicado em 23 de ago de 2013. Disponível em:

https://www.youtube.com/watch?v=SzqmiJLxmbc. Acesso em: 11 nov. 2014.

FACEBOOK, Criação da conta ou login. Disponível em: https://www.facebook.com. Acesso em: 18 nov. 2014.

MEC, Kit letramento. Disponível em: Disponível em:

https://www.google.com.br/search?q=kit+letramento+mais+educao. Acesso em: 11 nov. $\underline{2014 .}$

MENEZES, EbenezerTakunode; SANTOS, Thais Helena dos."CIEPs (Centros Integrados de Educação Pública)" (verbete). Dicionário Interativo da Educação Brasileira-EducaBrasil. São Paulo: Midiamix, 2002. Disponível em:

http://www.educabrasil.com.br/eb/dic/dicionario.asp?id=83. Acesso em: 5 dez. 2014.

MOLL, Jaqueline (Org.). Caminhos da educação integral no Brasil: direito a outros tempos e espaços educativos. Porto Alegre: Penso, 2012.

MOLL, Jaqueline. Um paradigma contemporâneo para educação integral. Pátio - Revista Pedagógica. Porto Alegre, n. 51. P. 12-15, ago/out, 2099b.

MÜLLER, Angélica. Qualidade no ensino superior: a luta em defesa do Programa Especial de Treinamento. Rio de Janeiro: Garamond, 2003.

ROJO, H. Roxane; MOURA, Eduardo (Orgs.).Multiletramentos na escola. São Paulo: Parábola, 2012.

ROJO, Roxane (Org.). Escola conectada: os multiletramentos e as TICs. São Paulo: Parábola, 2013.

SOARES, Magda. Alfabetização e letramento: caminhos e descaminhos. Revista Pátio n.29 fev./abr. 2004. 